\title{
The Uptake of Aliphatic Amides by Pseudomonas aeruginosa
}

\author{
BY W. J. BRAMMAR,* NORMA D. MCFARLANE \\ AND PATRICIA H. CLARKE \\ Department of Biochemistry, University College, London, W.C.1
}

(Received 1 February 1966)

\begin{abstract}
SUMMARY
The uptake of aliphatic amides by Pseudomonas aeruginosa 8602 was studied by using ${ }^{1-14} \mathrm{C}$-acetamide and ${ }^{1-{ }^{14}} \mathrm{C}-\mathrm{N}$-acetylacetamide (a nonmetabolizable analogue). ${ }^{1-14} \mathrm{C}$-acetamide was accumulated by the wildtype strains and by an amidase-negative mutant. The maximum ratio of internal to external concentration measured was $100: 1$. ${ }^{1-14} \mathrm{C}-\mathrm{N}$-acetylacetamide was concentrated by the wild-type strain and the maximum ratio of internal to external concentration measured was $80: 1$. No difference was detected in amide uptake as between induced and non-induced cultures of the wild-type or mutant strains. It is concluded that the organism possesses a constitutative permease for these amides. Cyanoacetamide had no significant effect on $\mathrm{N}$-acetylacetamide accumulation by the wild-type strain at concentrations which repressed amidase synthesis. Repression of amidase synthesis by amide analogue repressors is therefore not due to inhibition of amide uptake by the bacteria.
\end{abstract}

\section{INTRODUCTION}

Pseudomonas aeruginosa 8602 produces an aliphatic amidase which is induced by several substrate and non-substrate amides. Brammar \& Clarke (1964) studied the kinetics of amidase induction in exponentially growing cultures by using acetamide as a substrate inducer and $N$-acetylacetamide as a non-substrate inducer. Amidase was induced at a significant rate by 0.1-1 mm-acetamide or 1--10 $\mathrm{mm}-\mathrm{N}$-acetylacetamide, but there was no evidence from the kinetic data of an inducible permease system for accumulating amides within the organism. Induction by acetamide and by $N$-acetylacetamide was repressed by certain amide analogues, including cyanoacetamide and thioacetamide. The extent of repression by amide analogues in growing cultures was found to depend on the relative concentrations of the inducer and repressor amides. Carbon-starved organisms were induced to synthesize amidase by very low concentrations of inducers (10-100 $\mu \mathrm{M})$ and it was possible to show competitive repression by cyanoacetamide of induction by acetamide or $\mathrm{N}$-acetylacetamide (Clarke \& Brammar, 1964). One of the possible sites of action of the amide analogue repressors is the point of entry of amides into the bacterial cell. We have now made a direct investigation of the permeability of Pseudomonas aeruginosa 8602 to amides by examining the uptake of ${ }^{1-14} \mathrm{C}-N$-acetylacetamide by the

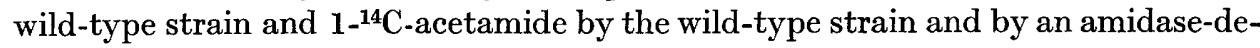
ficient mutant. The effect of cyanoacetamide on amide uptake was studied.

* Present address: Department of Biological Sciences, Stanford University, Palo Alto, California, U.S.A. 


\section{METHODS}

Organism. Our strain of $\boldsymbol{P}$ seudomonas aeruginosa was originally obtained from the National Collection of Type Cultures as NCTC 8602. By subculture in acetamide+ glucose medium we obtained strain 8602/A which was used in earlier investigations (Brammar \& Clarke, 1964). We have renamed strain 8602/A Pseudomonas aeruginosa 8602 , since it cannot now be confused with NCTC 8602 which is no longer maintained in the National Collection of Type Cultures. The parent strain Pseudomonas aeruginosa 8602 was maintained and grown as described by Brammar \& Clarke (1964). The amidase-deficient strain $a m_{10}$ was isolated from strain 8602 after treatment with the mutagenic agent ethylmethane sulphonate. Strain $a m_{10}$ produced no detectable amidase under any of the conditions tested (Skinner \& Clarke, 1965).

Media. The growth media used were those described by Brammar \& Clarke (1964). The standard minimal salts growth medium contained $0.02 \mathrm{M}$-sodium succinate. For the carbon-starved bacteria sodium succinate was used as the carbon source at $0.01 \mathrm{~m}$ and acetamide at $0.02 \mathrm{M}$, which restricted growth to about equiv. $0.4 \mathrm{mg}$. dry wt. bacteria/ml.

Amidase assay. Enzyme assays were made by measuring the transferase activity with acetamide as substrate (Brammar \& Clarke, 1964).

Amides. Acetamide was obtained from Hopkin \& Williams Ltd. and purified by recrystallizing twice from ethanol. ${ }^{1-14} \mathrm{C}$-acetamide $(1 \mathrm{mC} / \mathrm{m}-\mathrm{mole})$ was obtained from Merck, Sharpe \& Dohme of Canada Ltd. and purified by thin-layer chroma-

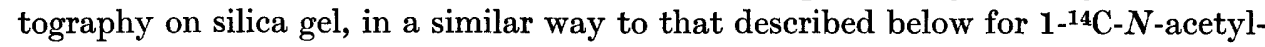
acetamide. ${ }^{1-14} \mathrm{C}-\mathrm{N}$-acetylacetamide was prepared as follows. ${ }^{1-14} \mathrm{C}$-acetamide $(5 \mathrm{mg}$.) and Analar acetic anhydride $\left(25 \mu \mathrm{l}\right.$.) were heated at $130^{\circ}$ in a sealed capillary tube attached to the bulb of a thermometer in an oil bath. After $4 \mathrm{hr}$ the sealed capillary tube was slowly cooled and opened. The reaction mixture was removed into a capillary tube of finer bore and applied to a freshly activated silica gel thin-layer plate. The solvent used for chromatography was toluene + ethanol $(80+20$, by vol. $)$ and unlabelled $\mathrm{N}$-acetylacetamide was used as an adjacent marker in a parallel track. The marker amides were converted into hydroxamates by spraying with a saturated solution of hydroxylamine hydrochloride in $80 \%(\mathrm{v} / \mathrm{v})$ methanol in water, containing $\mathrm{NaOH} 3 \%(\mathrm{w} / \mathrm{v})$ and heating at $100^{\circ}$ for $10 \mathrm{~min}$. The hydroxamates were detected by spraying with a solution of $\mathrm{FeCl}_{3}(10 \%, \mathrm{w} / \mathrm{v})+\mathrm{HCl}(0 \cdot 1 \%, \mathrm{w} / \mathrm{v})$ in $95 \%(\mathrm{v} / \mathrm{v})$ methanol in water.

The radioactive areas were detected by radioautography with Kodak X-ray films (Blue Band or Royal blue). The radioactive area of silica gel corresponding to the $\mathrm{N}$-acetylacetamide marker was removed with a spatula and the ${ }^{14} \mathrm{C}-\mathrm{N}$-acetylacetamide extracted with $1 \mathrm{ml}$. distilled water and stored at $-30^{\circ}$.

Uptake of ${ }^{14} \mathrm{C}$-amides. The ${ }^{14} \mathrm{C}$-amides were made up to the required concentration with unlabelled amide and added to the bacterial incubation mixtures. Samples ( $1 \mathrm{ml}$.) were pipetted onto Oxoid $3 \mathrm{~cm}$. membrane filters (Oxoid Ltd., London) or Millipore filters (V. A. Howe and Co. Ltd.), filtered under pressure and washed with about 10 vol. of ice-cold culture medium. The filters were dried at $80^{\circ}$ for $15 \mathrm{~min}$. and placed in phials containing $15 \mathrm{ml}$. scintillation fluid $(0.04 \mathrm{~g}$. $2-p$-phenylenebis-(5-phenyloxazole $)+4 \cdot 0 \mathrm{~g}$. 2:5-diphenyloxazole/l. toluene). The samples were 
counted in a Nuclear Chicago liquid scintillation counter which gave a counting efficiency of about $60 \%$ under the conditions used.

The retention volume of the membrane filters was determined by filtering a $1 \mathrm{ml}$. sample of cell-free labelled medium. After each experiment the radioactivity in the medium was determined by application of a $10 \mu \mathrm{l}$. sample to a filter, drying and counting.

\section{RESULTS}

\section{Uptake of $1{ }^{14} \mathrm{C}-\mathrm{N}$-acetylacetamide by carbon-starved bacteria}

The wild-type strain Pseudomonas aeruginosa 8602 was grown on limiting concentrations of acetamide to obtain induced bacteria, and on succinate to obtain non-induced bacteria. The uptake of ${ }^{1-14} \mathrm{C}-\mathrm{N}$-acetylacetamide by the washed

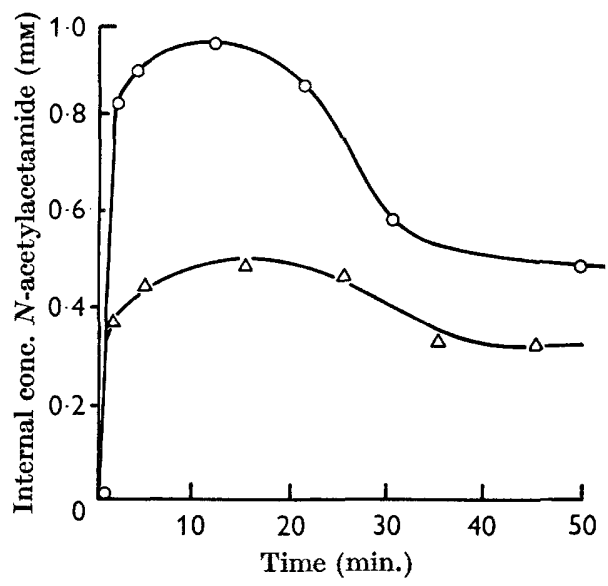

Fig. 1

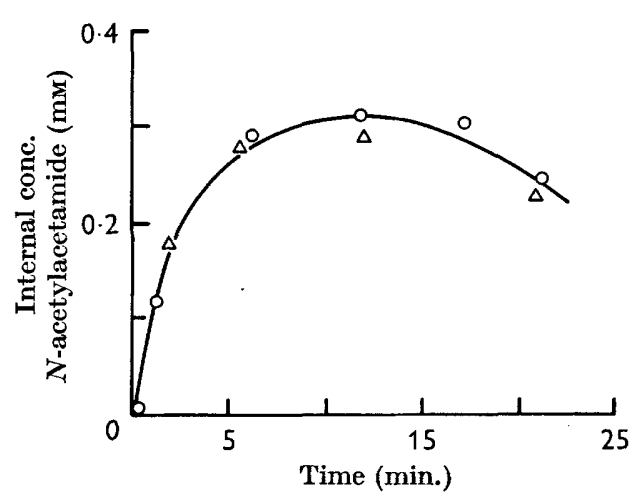

Fig. 2

Fig. 1. Uptake of ${ }^{14} \mathrm{C}-\mathrm{N}$-acetylacetamide by washed suspensions of Pseudomonas aeruginosa 8602 wild-type grown on limiting succinate. $10 \mu \mathrm{M}$ - $N$-acetylacetamide. $\mathrm{O}-\mathrm{O}$, incubated at $20^{\circ} ; \Delta-\Delta$, incubated at $37^{\circ}$.

Fig. 2. Uptake of ${ }^{14} \mathrm{C}-\mathrm{N}$-acetylacetamide by washed suspensions of Pseudomonas aeruginosa 8602 wild type grown on limiting succinate. Incubation at $20^{\circ}$ with $10 \mu \mathrm{M}$ $N$-acetylacetamide. $O-O$, control; $\Delta-\Delta$, with mM-cyanoacetamide.

carbon-starved bacteria was followed at $37^{\circ}$, and samples were removed for estimations of radioactivity at intervals during $30 \mathrm{~min}$. of incubation. Incorporation of radioactivity into the bacteria was rapid and there was no significant difference between the induced and non-induced bacteria. With $100 \mu \mathrm{M}-\mathrm{N}$-acetylacetamide the radioactivity taken up by the bacteria rapidly reached a plateau value with both bacterial preparations. It was known from previous work (Clarke \& Brammar, 1964) that acetamide-grown bacteria had a high amidase activity and that, under the conditions of the ${ }^{14} \mathrm{C}$ uptake experiments, succinate-grown carbon-starved bacteria were rapidly induced by $N$-acetylacetamide to form amidase. This experiment showed that there was no comparable induction of a permeability system for amide uptake since amidase-induced bacteria and non-induced bacteria behaved in similar ways.

The uptake of ${ }^{1-14} \mathrm{C}-\mathrm{N}$-acetylacetamide at $20^{\circ}$ by succinate-grown carbon-starved 
bacteria was compared with that at $37^{\circ}$. Figure 1 shows that the process was more rapid and reached a higher value at $20^{\circ}$ than at $37^{\circ}$. An initial rapid uptake reached a plateau value which declined after about $15 \mathrm{~min}$. to reach a new lower value. The internal concentration of $\mathrm{N}$-acetylacetamide in the experiment at $20^{\circ}$ was 80 times the external concentration at the plateau value and 40 times higher after about $30 \mathrm{~min}$. At $37^{\circ}$ the highest difference reached between the internal and external concentrations of $\mathrm{N}$-acetylacetamide was about 40 times.

Cyanoacetamide, which represses amidase induction by $\mathrm{N}$-acetylacetamide in carbon-starved bacteria had no effect on the uptake of $N$-acetylacetamide. Figure 2 shows the uptake of $10 \mu \mathrm{M}-1^{14} \mathrm{C}-N$-acetylacetamide in the presence and absence of mm-cyanoacetamide. Under these conditions repression of amidase synthesis was virtually complete (Clarke \& Brammar, 1964).

\section{The uptake of ${ }^{1-14} \mathrm{C}-\mathrm{N}$-acetylacetamide by exponentially growing bacteria}

The experiments with carbon-starved pseudomonads had shown that a concentration of cyanoacetamide which completely repressed amidase induction had no effect on the uptake of $N$-acetylacetamide by the bacteria. Similar results were obtained with growing cultures. A culture of Pseudomonas aeruginosa 8602 growing exponentially in succinate medium at $37^{\circ}$ was induced with $1{ }^{14} \mathrm{C}-\mathrm{N}$-acetylacetamide at about 8000 counts $/ \mathrm{min}$. $/ \mathrm{ml}$. and diluted with unlabelled $N$-acetylacetamide to give a final concentration $5 \mathrm{~mm}$. The culture was divided into two flasks to one of which cyanoacetamide was added to a concentration of $10 \mathrm{~mm}$. Samples were removed at intervals for determinations of growth, amidase activity and radioactivity. The rate of amidase synthesis was $90 \%$ repressed but there was no significant difference in the uptake of ${ }^{14} \mathrm{C}$ by the bacteria.

\section{Uptake of 1-14C-acetamide}

Acetamide permeation could not be properly studied in the wild-type Pseudomonas aeruginosa 8602 since it was impossible to separate the entry process from the further metabolism of acetamide. Acetamide was not hydrolysed by the amidasedeficient mutant strain $a m_{10}$ so that in this strain acetamide uptake reflects the transport process itself and not its coupling to intermediate metabolism. Acetamide uptake by strain $a m_{10}$ can be considered to be analogous to the uptake of a nonsubstrate inducer by the wild-type. ${ }^{1-14} \mathrm{C}$-acetamide uptake was followed with wild-type and mutant strains. The cultures were grown on succinate medium and harvested after about $2 \mathrm{hr}$ in the exponential growth phase; this provided the non-induced cultures. To obtain induced cultures, $N$-acetylacetamide to give a final concentration mu was added as soon as growth had started. Under these conditions wild-type bacteria are induced to synthesize amidase at a rapid rate. The bacteria were resuspended in succinate medium containing chloramphenicol $50 \mu \mathrm{g} . / \mathrm{ml}$. and the uptake of ${ }^{14} \mathrm{C}$-acetamide followed at $25^{\circ}$.

Figure 3 shows the uptake of ${ }^{1-{ }^{14}} \mathrm{C}$ acetamide by strain $a m_{10}$. The amount of radioactivity in the bacteria increased during the first $5 \mathrm{~min}$. and then reached a plateau which was maintained for 10-25 min. There was no significant difference between cultures grown in the presence or absence of the enzyme inducer. Uptake of ${ }^{1-14} \mathrm{C}$-acetamide by the wild-type gave similar results and again no significant difference was detected between induced and non-induced cultures. The values for 
${ }^{1-14} \mathrm{C}$-acetamide accumulation at the plateau by the wild type were approximately the same as those obtained with mutant strain $a m_{10}$. It was calculated from the experiments with strain $a m_{10}$ that the internal concentration of acetamide reached a maximum of about $40 \mu$ moles/g. dry wt. bacteria. This represents a ratio of internal to external concentration of 100:1.

Figure 3 also shows the results of typical experiments in which a 100-fold excess of non-radioactive acetamide was added to cultures of mutant strain $a m_{10}$ which had accumulated $1{ }^{14} \mathrm{C}$-acetamide. With both the induced and the non-induced cultures the radioactivity was displaced from the bacteria. The differences in the curves for induced and non-induced cultures are not significant. A similar experiment was made with an induced culture of the wild type but no displacement was detected. It was concluded that this was because the acetamide was being metabolized by the wild-type bacteria.
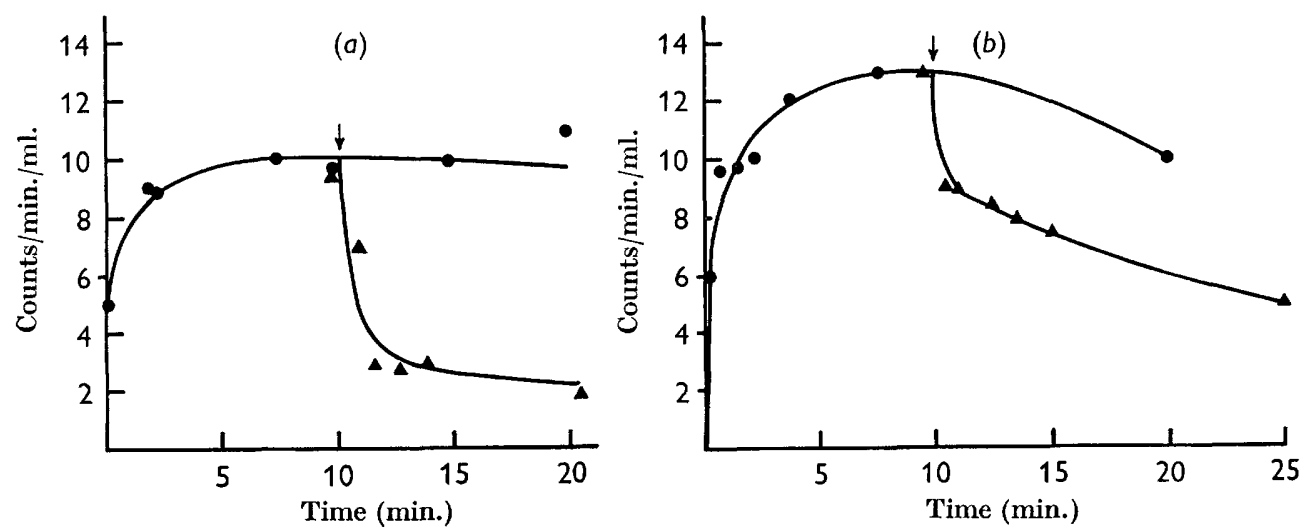

Fig. 3. Uptake of ${ }^{14} \mathrm{C}$-acetamide by washed suspensions of Pseudomonas aeruginosa 8602 amidase-deficient mutant strain $a m_{10} \cdot(a)$ non-induced bacteria, $(b)$ induced bacteria. $\longrightarrow-100 \mu \mathrm{M}^{-14} \mathrm{C}$-acetamide; $\Delta-\Delta, 100-\mu \mathrm{M}^{-14} \mathrm{C}$-acetamide, with $10 \mathrm{~mm}-{ }^{12} \mathrm{C}$-acetamide added at the time indicated by arrow.

${ }^{1-14} \mathrm{C}$-acetamide was recovered quantitatively and in an unaltered form from cultures of mutant strain $a m_{10}$. Samples $(1 \mathrm{ml}$.) of the incubation mixtures were taken at intervals after ${ }^{1-14} \mathrm{C}$-acetamide had been added (5-25 min.), centrifuged, the pellets washed with ice-cold medium and disrupted by resuspending in $\mathbf{0 \cdot 2 5} \mathrm{ml}$. ice-cold acetone $50 \%(\mathrm{v} / \mathrm{v})$ in water. Samples of the acetone extracts of the bacteria were counted and also subjected to thin-layer chromatography and radioautography. From each of the extracts only one radioactive spot was obtained which corresponded with the acetamide marker. The total count of radioactivity in $1 \mathrm{ml}$. of extract was $8400 / \mathrm{min}$. and that of the acetamide spot on the chromatogram to which $0.25 \mathrm{ml}$. of the extract had been applied was $2000 / \mathrm{min}$.

\section{DISCUSSION}

Considerable evidence has now been obtained for the existence in bacteria of stereospecific permeation systems which mediate the entry of organic compounds into bacteria. The term 'permease' was suggested to designate the specific proteins involved, and the most detailed studies of these systems have been made on 
$\beta$-galactoside permease of Escherichia coli (Cohen \& Monod, 1957; Kepes \& Cohen, 1962; Fox \& Kennedy, 1965). The existence of permease systems in Pseudomonas aeruginosa for the transport of intermediates of the tricarboxylic acid cycle was suggested by the work of Barrett \& Kallio (1953), Kogut \& Podoski (1953) and Clarke \& Meadow (1959). Kepes \& Cohen (1962) suggested that the following conditions should be the minimal requirement to demonstrate the existence of a permease : (1) accumulation of a natural substrate above the external concentration; (2) accumulation of a non-metabolizable analogue; (3) specific crypticity as opposed to normal utilization; (4) specific crypticity for a substrate analogue known to compete for metabolic enzymes in vitro. These conditions can only be fully satisfied when mutants are available which lack the specific permease and the specific enzymes of the metabolic pathway, In the present work we were concentrating on certain aspects of amide permeation. We wished to establish whether or not amides were concentrated by the bacteria, and if so whether the system was inducible and what effect repressors of amide induction had on the process.

${ }^{14} \mathrm{C}-\mathrm{N}$-acetylacetamide was concentrated by wild-type Pseudomonas aeruginosa 8602 above the external concentration and no difference was observed between non-induced bacteria and bacteria induced to form amidase by growth on acetamide. The uptake of ${ }^{1-14} \mathrm{C}$-acetamide by an amidase-deficient mutant strain $a m_{10}$, was similar to the uptake found for ${ }^{14} \mathrm{C}-\mathrm{N}$-acetylacetamide by the wild type. With strain $a m_{10}$ the initial rate of accumulation and the maximum internal concentration of amide again showed no significant difference between induced and non-induced cultures. Extraction of bacteria with aqueous acetone showed that the radioactivity was entirely due to free ${ }^{1-14} \mathrm{C}$-acetamide. The accumulated ${ }^{1-14} \mathrm{C}$-acetamide was displaced by adding excess of labelled acetamide. Induced and non-induced wild-type cultures were also shown to accumulate $\mathbf{1}^{-14} \mathrm{C}$-acetamide. No displacement of radioactivity by unlabelled acetamide was detected with induced cultures of the wild-type strain, presumably because the acetamide was metabolized by the bacteria. These results satisfy the first two requirements of Kepes \& Cohen (1962) for demonstrating the existence of a permease, i.e. the internal accumulation of a natural substrate and a non-metabolizable analogue above the external concentration. The identical behaviour of induced and non-induced cultures indicated that the amide permease was constitutive. Although both $\beta$-galactosidase and $\beta$-galactoside permease of Escherichia coli are inducible, Horecker, Thomas \& Monod (1960) showed that galactose permease is constitutive while the enzymes for the initial steps in galactose utilization are inducible. Permeases for $\alpha$-glucosides and amino acids are also constitutive in $\boldsymbol{E}$. coli (Kepes \& Cohen, 1962).

The effects of temperature on $N$-acetylacetamide uptake are similar to those described by Kepes \& Cohen (1962) for the $\beta$-galactoside permease of Escherichia coli. The accumulation of thiomethyl- $\beta$-D-galactoside by a suspension of $\boldsymbol{E}$. coli can be increased by a factor of 5 by lowering the temperature from $34^{\circ}$ to $14^{\circ}$. We made no detailed studies on the kinetics of $N$-acetylacetamide and acetamide uptake by $P$ seudomonas aeruginosa 8602 at different external concentrations, but the maximum ratio of internal to external concentration found was $80: 1$ for $\mathrm{N}$-acetylacetamide at $20^{\circ}$ and 100:1 for acetamide at $25^{\circ}$. For $E$. coli $\beta$-galactoside permease, values have been calculated for maximum ratios of internal to external concentration of 5 for o-nitrophenyl- $\beta$-D-galactoside to $\mathbf{2 0 0 0}$ for lactose. 
From previous work it had been concluded that the amide analogue repressor cyanoacetamide competed directly with the inducer $N$-acetylacetamide (Clarke \& Brammar, 1964). Enzyme induction by $N$-acetylacetamide is very sensitive to repression by cyanoacetamide. With exponentially growing cultures of Pseudomonas aeruginosa 8602 , induction by $10 \mathrm{~mm}-N$-acetylacetamide is $84 \%$ repressed by $100 \mu \mathrm{M}$-cyanoacetamide, while repression of induction by mM-acetamide requires a 10-fold excess of cyanoacetamide. We concluded that the three amides had affinities for an inducer binding site in the order acetamide $>$ cyanoacetamide $\gg N$ acetylacetamide. The most sensitive system to test whether this site was at the point of entry of amides into the organism was the effect of cyanoacetamide on the uptake of $\mathrm{N}$-acetylacetamide. At concentrations of cyanoacetamide sufficient to repress enzyme synthesis completely no effect of cyanoacetamide on ${ }^{1-14} \mathrm{C}-\mathrm{N}$-acetylacetamide uptake by $P$ seudomonas 8602 was detected. We conclude that the site of competition cannot be at the point of entry into the organism, but must be at a site within it. The most probable site for competition of amide analogue repressors with inducer amide is the inducer binding site of a cytoplasmic repressor molecule produced by a regulator gene (Jacob \& Monod, 1961).

We are grateful to the Medical Research Council for a grant towards the cost of this research.

\section{REFERENCES}

Barrett, J. T. \& Kallyo, R. E. (1953). Terminal respiration in Pseudomonas fluorescens. Component enzymes of the tricarboxylic acid cycle. J. Bact. 66, 517.

Brammar, W. J. \& Clatke, P. H. (1964). Induction and repression of Pseudomonas aeruginosa amidase. J. gen. Microbiol. 37, 307.

Clarke, P. H. \& Brammar, W. J. (1964). Regulation of bacterial enzyme synthesis by induction and repression. Nature, Lond. 203, 1153.

Clarke, P. H. \& Meadow, P. M. (1959). Evidence for the occurrence of permeases for tricarboxylic acid intermediates in Pseudomonas aeruginosa. J. gen. Microbiol. 20, 144.

Cohen, G. N. \& Monod, J. (1957). Bacterial permeases. Bact. Rev. 21, 169.

Fox, C. F. \& Kennedy, E. P. (1965). Specific labelling and partial purification of the M protein, a component of the $\beta$-galactoside transport system of Escherichia coli. Proc. natn. acad. Sci., U.S.A. 54, 891.

Horecker, B. L., Thomas, J. \& Monod, J. (1960). Galactose transport in Escherichia coli. 1. General properties as studied in a galactokinase-less mutant. J. biol. Chem. 235, 1580.

$\mathrm{J}_{\mathrm{ACOB}}$, F. \& Monod, J. (1961). Genetic regulatory mechanisms in the synthesis of proteins. J. mol. Biol. 3, 318.

Kepes, A. \& Cohen, G. N. (1962). Permeation. In The Bacteria, vol. 4, p. 199. New York: Academic Press.

Kogut, M. \& Podoski, E. P. (1953). Oxidative pathways in a fluorescent Pseudomonas. Biochem. J. 55, 800.

Skinner, A. J. \& Clarke, P. H. (1965). $\mathrm{C}_{2}$ mutants of Pseudomonas aeruginosa. J. gen. Microbiol. 39, viii. 